\title{
PENGEMBANGAN PROTOTYPE FREQUENTLY ASKED QUESTION (FAQ) UNDIKSHA DENGAN PENDEKATAN USER CENTERED DESIGN
}

\author{
I Ketut Resika Arthana ${ }^{1)}$, Gede Rasben Dantes ${ }^{2)}$, Luh Joni Erawati Dewi³), Komang \\ Setemen ${ }^{4}$, Ni Wayan Marti ${ }^{5}$ \\ 1,2,3,4,5 Jurusan Teknik Informatika, Fakultas Teknik dan Kejuruan, Universitas Pendidikan Ganesha \\ Email: ${ }^{1}$ resika@undiksha.ac.id, ${ }^{2}$ rasben.dantes@undiksha.ac.id, 3joni.erawati@undiksha.ac.id, \\ ${ }^{4}$ k.setemen@undiksha.ac.id, ${ }^{5}$ wayan.marti@undiksha.ac.id
}

\begin{abstract}
ABSTRAK
Penelitian ini bertujuan untuk mengembangkan Prototype Frequently Asked Question(FAQ) di Universitas Pendidikan Ganesha (Undiksha) dengan pendekatan User Centered Design(UCD). FAQ merupakan sistem yang memfasilitasi pengguna layanan mendapatkan jawaban terkait pertanyaan yang sering diajukan pada penyelenggaraan layanan tertentu. Pengembangan sistem ini dibutuhkan untuk memudahkan penyedia layanan dalam menjawab pertanyaan yang sering muncul. Studi kasus pengembangan FAQ ini adalah di Undiksha, mengingat Undiksha menyelenggarakan berbagai kegiatan yang melibatkan banyak pengguna seperti mahasiswa, dosen, pegawai dan masyarakat luas. Jika setiap pertanyaan dijawab langsung oleh operator kegiatan, maka akan membutuhkan waktu, biaya dan tenaga. Secara garis besar, dalam sistem FAQ Undiksha terlibat aktor pengguna layanan dan operator kegiatan. Karakteristik pengguna sistem FAQ ini beragam dengan kemampuan pengoperasian IT yang berbeda-beda, untuk itu pada penelitian ini menggunakan pendekatan UCD. Tahapan UCD meliputi Understand and specify the context of use, Specify the user and organizational requirements, Produce design solutions (prototypes) dan Evaluate designs with users against requirements. Hasil pengembangan prototype UCD adalah working prototype yang menggambarkan alur kerja sistem $F A Q$ dari sisi pengguna layanan. Hasil pengujian usability dengan standar ISO 9241-11 pada iterasi pertama menunjukkan bahwa prototype FAQ Undiksha memiliki Efektifitas 87\%, Efesiensi 98\% dan Kepuasan pengguna dengan nilai 80.5 . Meskipun nilai efektifitas tergolong tinggi, namun pada iterasi pertama, terdapat permasalahan usability pada task keempat, sehingga setelah dilakukan perbaikan tingkat efektifitas meningkat menjadi 93\%.

Kata kunci: Frequently Asked Question, User Centered Design, Usability
\end{abstract}

\begin{abstract}
This research aims to develop the prototype of Frequently Asked Questions (FAQ) at Universitas Pendidikan Ganesha (Undiksha) by using a User-Centered Design approach. The purpose of the FAQ system is to facilitate users in receiving a swift response towards the proposed questions. The case study of this research was held at Undiksha because Undiksha often held various events that involved many users, such as: students, lecturers, staff, and the public. If all questions are answered by customer services, it is time and cost consuming. The actors in this prototype consist of customer services and the users. Due to various demographics and characteristics of users, we need to facilitate user needs. So in this research we are intended to use a User-Centered Design approach. The phases in the User-Centered Design are: understand and specify the context of use, specify the user and organizational requirements, produce design solutions (prototypes) and evaluate designs with users against requirements. The product of this research is a working prototype of FAQ Undiksha. Afterwards, we evaluated the prototype with ISO 9241-11 usability testing and got the following results, such as: effectivity $87 \%$, efficiency $98 \%$, and user satisfaction 80.5 . Although the score for the effectiveness is relatively high, the usability problem found at the fourth task. We improved on the prototype of the FAQ and the score of effectiveness increased to $93 \%$.
\end{abstract}

Keywords : Frequently Asked Question, User Centered Design, Usability 


\section{PENDAHULUAN}

Salah satu indikator keberhasilan organisasi adalah menyelenggarakan pelayanan informasi yang sesuai dengan kebutuhan pengguna. Pemberian informasi yang berkualitas sangat penting dilakukan agar pengguna mendapatkan gambaran mengenai layanan yang disediakan. Informasi yang berkualitas meliputi informasi yang akurat, tepat waktu dan relevan. Informasi yang akurat membantu pengguna mendapatkan informasi yang benar, informasi yang tepat waktu sesuai dengan saat informasi tersebut dibutuhkan dan informasi yang relevan sesuai dengan kebutuhan dan bermanfaat bagi pengguna. Saat ini dengan berkembangnya teknologi, sebagian besar organisasi memberikan informasi layanan melalui website. Jika informasi yang ingin dicari oleh pengguna tidak ada pada website, maka pengguna memilih bertanya langsung dengan penyedia layanan baik secara langsung, melalui chat maupun telepon.

Permasalahan yang sering muncul saat petugas layanan informasi berkomunikasi langsung dengan pengguna adalah keterbatasan komunikasi karena terbatasnya waktu, tenaga dan biaya. Sebagai contoh dalam penyelenggaran penerimaan mahasiswa baru di Undiksha, petugas layanan informasi sebagai penyedia layanan harus melayani penyediaan informasi untuk sekitar 2000 calon mahasiswa. Sebagian besar informasi yang ditanyakan sudah ada pada website, namun karena keterbatasan akses atau kurang representatifnya informasi, dan pengguna lebih suka untuk bertanya langsung maka petugas layanan informasi harus melayani banyak pertanyaan dari calon mahasiswa. Dalam melayani pertanyaan calon mahasiswa, sebagian besar pertanyaan yang sudah diajukan lagi, diajukan kembali. Permasalahan lain adalah beragamnya pengetahuan petugas layanan informasi berpotensi memberikan jawaban yang tidak konsisten.

Solusi dari permasalahan tersebut adalah dengan menyediakan sistem informasi yang menampung pertanyaan-pertanyaan pengguna yang sering diajukan beserta jawabannya. Manfaat dari sistem tersebut adalah menyediakan layanan bagi pengguna untuk mencari pertanyaan yang sering diajukan dan juga sebagai sumber pengetahuan atau Knowledge Management System (KMS) bagi petugas layanan informasi. Pengembangan KMS sangat dibutuhkan oleh organisasi untuk merekam pengetahuan yang terkait dengan organisasi tersebut. Selain itu, pengembangan KMS bertujuan untuk mengatasi masalah hilangnya pengetahuan(Knowledge Walkout) karena pergantian staff(TurnOver). Knowledge Management terdiri dari proses mendapatkan, mengelola dan membagi pengetahuan dalam suatu organisasi. Komponent KMS terdiri dari Orang, Proses dan Teknologi [1]. Beberapa contoh penerapan KMS pada organisasi diantaranya adalah Penerapan Knowledge Management System (KMS) Berbasis Web [2], Pengembangan Knowledge Management System Pada Bina Nusantara Berbasis Microsoft Sharepoint 2010 [3], Analisis Knowledge Management System Readiness Di Universitas Amikom Purwokerto Berdasarkan Aspek People, Process, Technology [4] dan Developing Conceptual Governance Model For Collaborative Knowledge Management System In Public Sector Organisations [5].

Salah satu penerepan sistem KMS adalah Frequently Asked Question (FAQ). Sistem FAQ merupakan salah satu bentuk implementasi dari sistem Knowledge Management System(KMS) yang mana berfungsi untuk mengelola pengetahuan. Pengelolaan pengetahuan ini berfungsi agar pengetahuan terdistribusi dengan maksimal. Sistem FAQ sudah banyak dikembangkan baik untuk kebutuhan organisasi maupun penelitian.

Dalam pengembangan sistem, aspek yang penting diperhatikan adalah aspek kemudahan pengguna dalam menggunakan sistem sesuai dengan tujuannya yang sering disebut dengan usability. Usability merupakan ukuran sejauh mana suatu produk dapat digunakan oleh pengguna dalam konteks tertentu untuk mencapai tujuannya. Penelitian menunjukkan bahwa sistem yang mudah digunakan akan meningkatkan efek aksi positif yang berhubungan dengan pembelian, mengingat dan meningkatkan kunjungan website serta meningkatkan pembelian produk. Disamping itu, website yang mudah digunakan juga mengurangi biaya pengembangan, support dan biaya pemeliharaan [6]. Sesuai standar Jakob Nelson, usability memiliki atribut Learnability, Efficiency, Memorability, Errors dan Satisfaction [7]. Standar lain yang sering digunakan dalam penelitian usability adalah standar ISO 9241-11 yang meliputi effectiveness, efficiency, dan satisfaction. Pengujian Usability dengan standar ISO 9241-11 sudah banyak dilakukan, diantaranya adalah pengujian usability pada website wadaya[8]. Agar mencapai tujuan pengembangan sistem yang memenuhi aspek usability, maka dalam proses pengembangan sistem harus berfokus pada pengguna sehingga sistem yang dihasilkan memenuhi ekspektasi pengguna. Pendekatan pengembangan sistem yang dalam setiap tahapannya melibatkan pengguna adalah pendekatan UCD.

UCD merupakan pendekatan dalam mendesain sistem berdasarkan keterlibatan aktif pengguna untuk meningkatkan pemahaman terhadap karakteristik pengguna dan kebutuhan sistem. UCD 
dipercaya sebagai kunci sukses suatu sistem memenuhi kaidah kebermanfaatan(Usefulness) dan kedayabergunaan (Usability). UCD sudah menjadi standar yang didefinisikan pada ISO 13407 dan berhubungan dengan laporan teknis ISO TR 18529 [9]. Penerapan pendekatan UCD dalam pengembangan sistem sangat penting agar pengguna nyaman menggunakan sistem yang disediakan. Kesadaran penggunaan UCD dalam pengembangan sistem seiring dengan perkembangan $E$ Commerce yang mana pengguna menginginkan menjalankan bisnisnya dari mana saja hanya dengan satu klik. Website yang dikembangkan dengan desain yang buruk berpotensi menyebabkan pengguna berpindah atau tidak memanfaatkan layanan yang diisediakan [10].

Pengembangan sistem FAQ sudah banyak dilakukan, namun saat ini belum ada penelitian yang secara eksplisit menyatakan menggunakan metode pendekatan user Center design. Pada penelitiian ini dikembangkan sistem FAQ dengan pendekatan UCD dengan studi kasus di Undiksha dan dengan pengujian Usability.

\section{METODE}

Metode yang digunakan dalam penelitian ini adalah UCD Gambar 1. UCD terdiri dari (1) Understand Content of Use, (2)Specify User Requirements, (3)Design Solution, (4) Evalute Against Requirements .

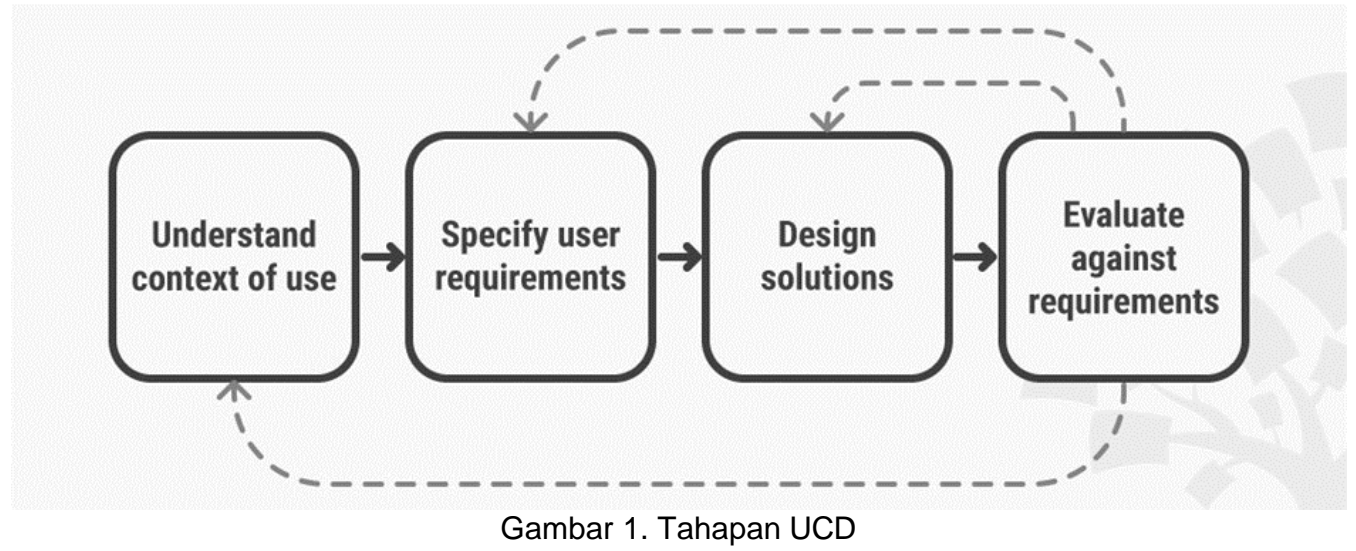

\section{A. Understand context of use}

Pada tahapan ini, tim peneliti memahami konteks penggunaan sistem yang dikembangkan. Salah satu observasi yang dilakukan adalah dengan studi kasus pada kegiatan penerimaan mahasiswa baru Undiksha yang berkomunikasi melalui grup telegram. Grup ini diikuti oleh panitia penerimaan mahasiswa baru dan juga calon mahasiswa baru yang berjumlah sekitar 2007 anggota. 


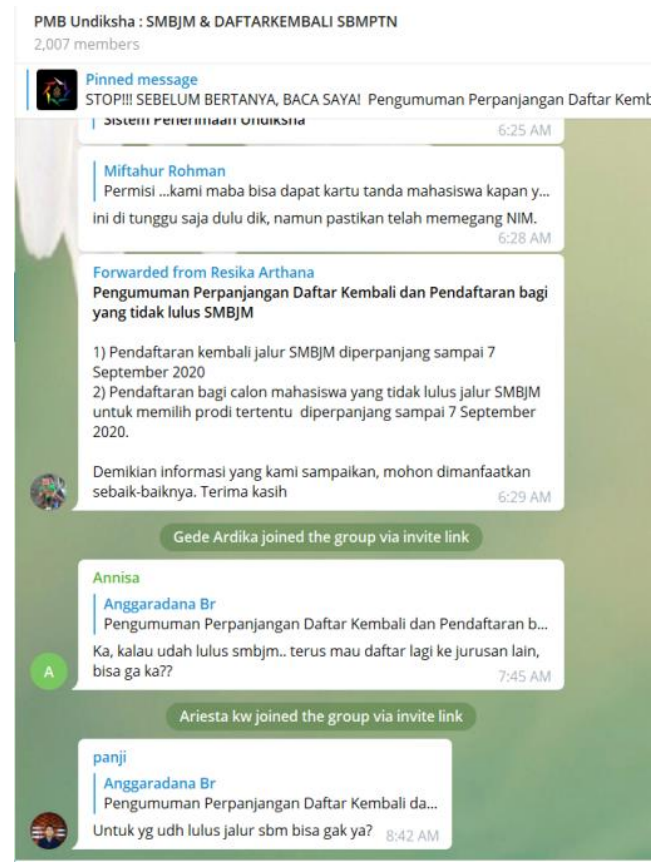

Gambar 2. Grup Telegram Penerimaan Mahasiswa Baru Undiksha

Berdasarkan studi literatur, observasi dan wawancara dengan pengelola dan pengguna dapat ditentukan konteks penggunaan sistem ini adalah :

1. Memudahkan pengguna layanan dalam mendapatkan jawaban terkait pertanyaan yang diajukan.

2. Memudahkan penyedia layanan dalam mengelola pengetahuan sehingga pengetahuan mengenai layanan tersebut tersimpan, terproses dan bisa terdistribusi sesuai kebutuhan.

3. Menghemat tenaga dan waktu, terutama tidak perlu harus komunikasi langsung secara terus menerus dan menjawab pertanyaan yang berulang-ulang.

4. Dalam organisasi(dalam hal ini studi kasus Undiksha), memiliki banyak kegiatan dengan layanan informasi, tim helpdesk dan pengguna berbeda-beda. Hendaknya sistem yang dihasilkan memfasilitasi kebutuhan tersebut.

Bedasarkan konteks kebutuhan sistem $F A Q$, dapat ditentukan bahwa pengguna yang akan terlibat adalah:

1. Administrator : mengelola sistem FAQ secara keseluruhan. Administrator bertugas untuk membuat jenis layanan dan menugaskan operator. Contoh skenario : Pada tahun 2021, Panitia Penerimaan Mahasiswa baru ingin memanfaatkan layanan FAQ Undiksha mengelola pengetahuan terkait penerimaan mahasiswa baru, maka administrator menambahkan layanan yang disebut dengan "Penerimaan Mahasiswa Baru 2021" dengan menugaskan beberapa operator kegiatan yang bertanggungjawab mengelola pengetahuan tersebut.

2. Operator kegiatan : operator yang bertugas mengelola pengetahuan yang terdiri dari daftar pertanyaan beserta jawabannya berdasarkan kegiatan yang diselenggarakan.

3. Pengguna layanan : merupakan pengguna yang memanfaatkan layanan untuk mencari informasi berdasarkan pertanyaan yang diajukan. Pengguna layanan terdiri dari dari jenis, yaitu pengguna terdaftar dan tidak terdaftar. Pengguna terdaftar memiliki hak akses untuk menulis pesan langsung ke operator kegiatan jika pengguna tidak menemukan jawaban yang diajukan.

Selain itu, dalam proses pemahaman konteks penggunaan ditentukan bahwa karakteristik pengguna sistem ini adalah sebagian besar berumur 18-25 tahun (mahasiswa), sisanya adalah 30-70 tahun(Dosen, pegawai dan masyarakat umum). Sistem ini akan digunakan untuk merekam pengetahuan terkait suatu bisnis proses, dan digunakan untuk mencari pengetahuan yang terekam berdasarkan pertanyaan yang diajukan. 


\section{B. Specify user requirements}

Pada tahapan ini, peneliti bersama calon pengguna yang terdiri dari calon operator layanan dan pengguna sistem berdiskusi untuk menentukan fitur-fitur yang sebaiknya disediakan pada sistem FAQ. Calon operator layanan yang sebelumnya berpengalaman menjawab pertanyaan pengguna mengutarakan permasalahan dan solusi alternatif yang perlu dilakukan. Berdasarkan diskusi dan observasi terhadap sistem sejenis, terdapat permasalahan yang muncul meliputi:

1) Banyaknya pertanyaan yang berulang-ulang. Hal ini disebabkan banyak pengguna yang tidak membaca pertanyaan dan jawaban yang sudah disampaikan sebelumnya. Hal ini menyebabkan tim helpdesk menambah beban kerja helpdesk

2) Layanan terbatas pada jam kerja kantor. Hal ini membuat pengguna menunggu untuk mendapatkan jawaban jika bertanya diluar jam kerja. Seharusnya dengan perkembangan teknologi sistem informasi saat ini, layanan bisa dilakukan 24 jam.

3) Jumlah helpdesk yang terbatas, banyaknya kegiatan, dan pertanyaan yang banyak dari pengguna merupakan hambatan tersendiri dalam menyediakan pelayanan.

Berdasarkan permasalahan di atas, dapat ditentukan daftar kebutuhan sistem pada sistem FAQ adalah sebagai berikut:

1) Pengguna Layanan

a. Bisa melakukan pencarian jawaban dengan cara memasukkan kata kunci pertanyaan

b. Bisa melihat daftar pertanyaan yang sering diajukan

c. Bisa memberikan penilaian kualitas jawaban

d. Bisa menghubungi operator kegiatan jika tidak menemukan jawaban yang sesuai

2) Operator Kegiatan

a. Bisa menambahkan daftar pertanyaan beserta jawaban

3) Administrator

b. Bisa menjawab pertanyaan yang diajukan oleh pengguna

a. Mengelola daftar kegiatan dan unit pengelola

b. Menugaskan operator kegiatan

\section{DESIGN SOLUTIONS}

Berdasarkan daftar kebutuhan fungsional di atas, selanjutnya disusun prototype yang mengambarkan user flow (alur proses pengguna) sistem secara visual. Sesuai dengan konsep UCD, dalam pengembangan solusi desain harus selalu melibatkan calon pengguna. Dalam penelitian ini, penyusunan user flow dilakukan dan diuji dengan 15 calon pengguna layanan untuk dimintakan sarannya. Pada penelitian ini, solusi desain yang difokuskan adalah dari sisi user flow pengguna layanan. 


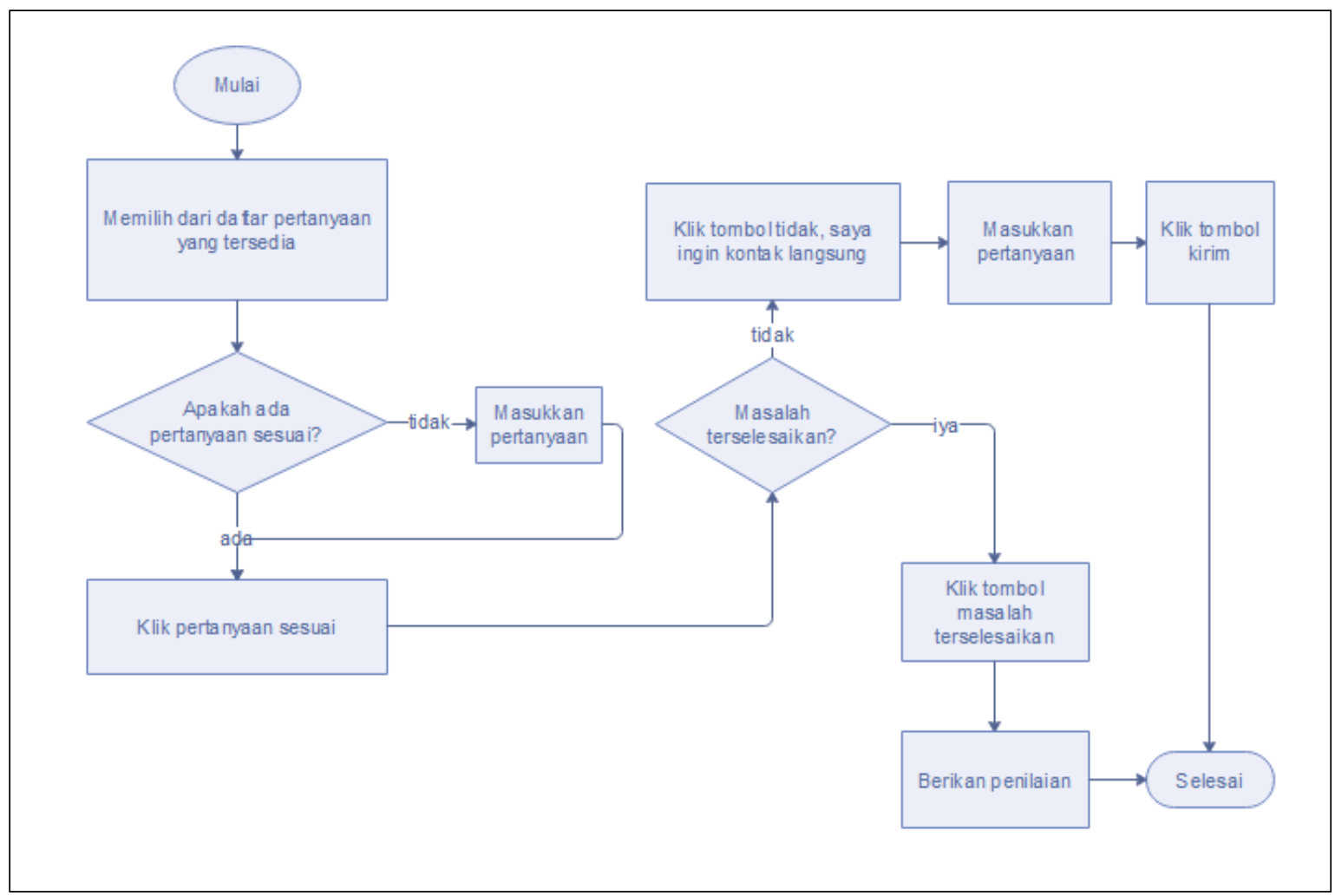

Gambar 3. User flow Pengguna Layanan

Sesuai dengan user flow pada Gambar 3, aktifias pengguna layanan dimulai dari membuka halaman website kemudian mencari solusi permasalahan melalui daftar pertanyaan yang sudah disediakan (Gambar 4). Jika permasalahan sudah ada pada daftar pertanyaan, maka pengguna layanan hanya perlu klik pertanyaan tersebut untuk melihat jawabannya (Gambar 5). Jika daftar permasalahan yang dicari tidak ada pada daftar pertanyaan, selanjutnya penguna layanan memasukkan kata kunci pada kolom yang disediakan. Jika pertanyaan yang dipilih memberikan solusi terkait permasalahaan yang dihadapi, maka pengguna layanan diharapkan mengklik tombol permasalahan terselesaikan dan selanjutnya memberikan penilaian (Gambar 6). Namun jika masalah belum terselesaikan, maka pengguna diberikan kesempatan menulis secara lengkap pertanyaannya dan dikirim ke pengelola layanan untuk dicarikan solusinya (Gambar 7). 


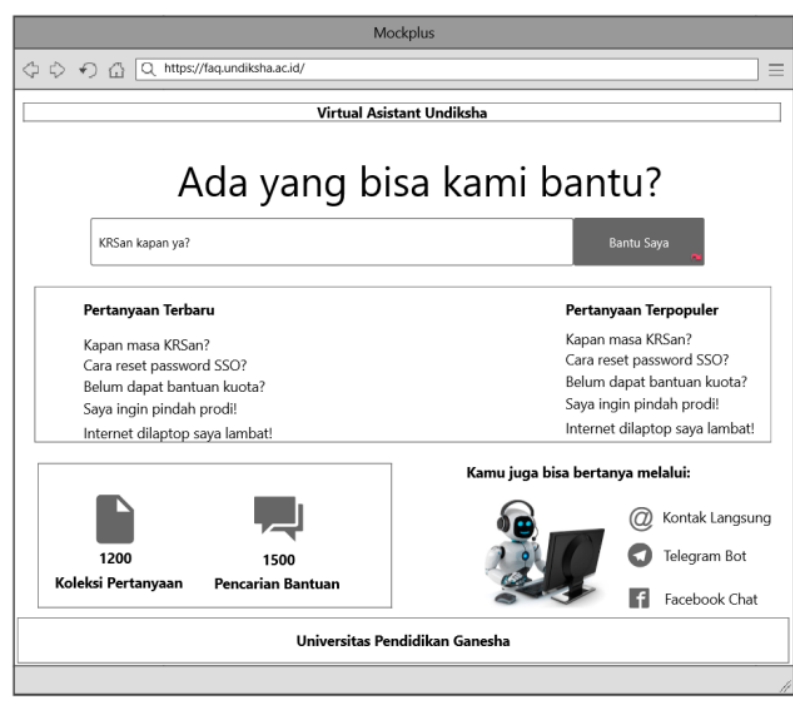

Gambar 4. Halaman Utama FAQ

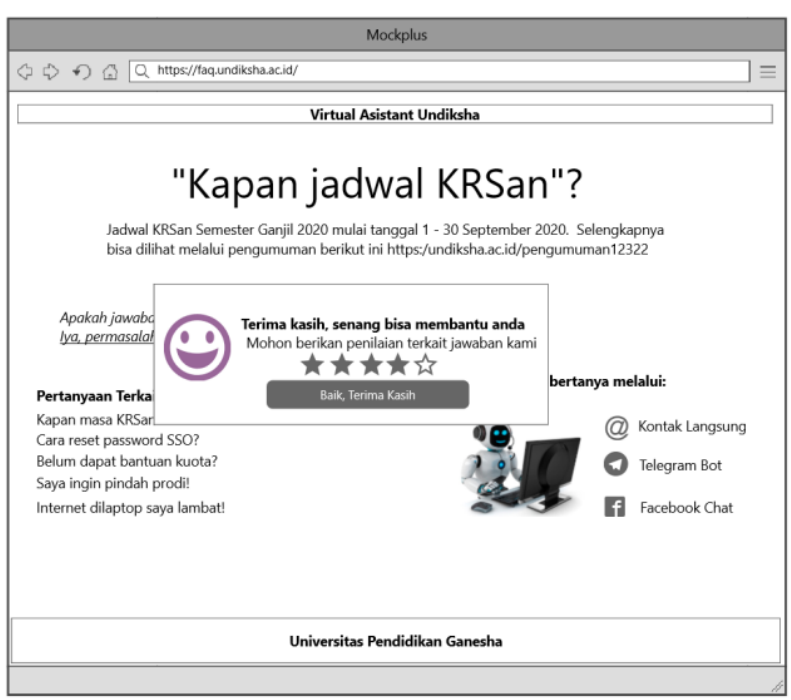

Gambar 6. Halaman Penilaian

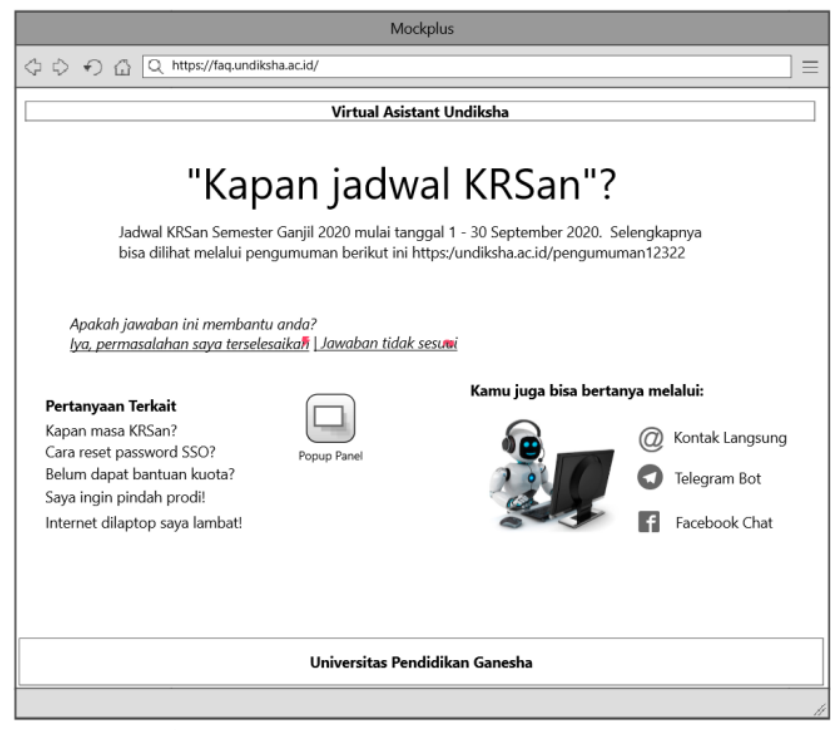

Gambar 5. Halaman Jawaban

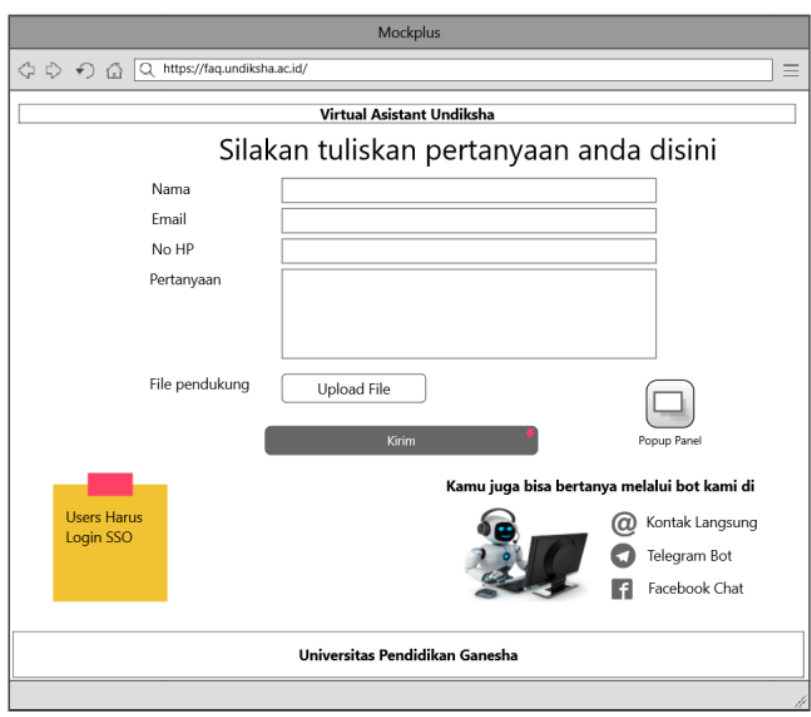

Gambar 7. Halaman Input Pertanyaan

\section{EVALUATE AGAINST REQUIREMENT}

Pada tahapan ini, dilakukan evaluasi terhadap desain yang sudah dihasilkan pada tahapan sebelumnya. Evaluasi yang dilakukan adalah Usability Testing dengan menggunakan standar ISO 9241-11 yang terdiri dari atribut kualitas Efektifitas, Efisiensi dan Kepusan Pengguna. Pengukuran efektifitas bertujuan untuk menentukan tingkat keberhasilan pengguna dalam melaksanakan tugasnya pada sistem, efisiensi mengukur banyaknya waktu yang dibutuhkan oleh pengguna dalam menyelesaikan tugasnya, sedangkan kepuasan pengguna menunjukkan tingkat kepuasan pengguna dalam menggunakan sistem. Pada penelitian ini, efektivitas dan efisiensi diukur berdasarkan task skenario yang diberikan kepada pengguna dan kepuasan pengguna diukur berdasrkan kuisioner SUS. Adapun tahapan pengujian usability pada sistem FAQ Undiksha meliputi perencanaan, penentuan peserta test, pelaksanaan test dan mengembangkan rekomendasi serta perbaikan prototype (Gambar 8). 


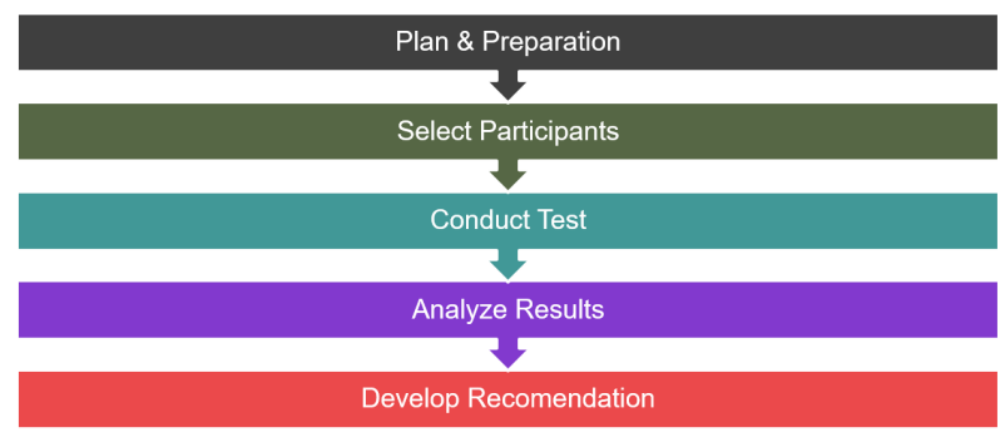

Gambar 8. Alur pengujian Usability

\section{a) Plan \& Preparation}

Pada tahap perencanaan, dikembangkan task skenario yang terdiri dari tugas-tugas yang harus diselesaikan oleh responden dalam sistem FAQ. Adapun tugas tersebut seperti tabel

Tabel 1. Daftar Tugas untuk Pengujian Usability

\begin{tabular}{|c|c|c|c|}
\hline No & Inisialisasi & Tugas & Aktivitas yang diharapkan \\
\hline 1 & Halaman utama & $\begin{array}{l}\text { Anda ingin mengetahui cara } \\
\text { reset password SSO, apa } \\
\text { yang akan anda lakukan? }\end{array}$ & $\begin{array}{l}\text { Kondisi : pada daftar pertanyaan yang } \\
\text { ditampilkan di halaman utama, sudah ada } \\
\text { pertanyaan "Bagaimana cara reset } \\
\text { password Email?" } \\
\text { Diharapkan responden memilih langsung } \\
\text { pertanyaan tersebut }\end{array}$ \\
\hline 2 & Halaman Utama & $\begin{array}{l}\text { Anda ingin mengetahui cara } \\
\text { mengunduh kartu hasil studi }\end{array}$ & $\begin{array}{l}\text { Kondisi : pada daftar pertanyaan yang } \\
\text { ditampilkan di halaman utama, belum ada } \\
\text { pertanyaan terkait unduh hasil studi. } \\
\text { Diharapkan responden menulis } \\
\text { pertanyaannya pada kolom yang telah } \\
\text { disediakan }\end{array}$ \\
\hline 3 & Halaman jawaban & $\begin{array}{l}\text { Jika anda menganggap } \\
\text { bahwa jawaban yang tampil } \\
\text { menyelesaikan masalah } \\
\text { anda }\end{array}$ & $\begin{array}{l}\text { Diharapkan responden memilih tombol lya } \\
\text { permasalahan saya terselesaikan. }\end{array}$ \\
\hline 4 & Halaman jawaban & $\begin{array}{l}\text { Jika anda menganggap } \\
\text { bahwa jawaban yang tampil } \\
\text { tidak menyelesaikan } \\
\text { masalah anda }\end{array}$ & $\begin{array}{l}\text { Responden memilih tombol "Saya tidak } \\
\text { menemukan jawaban sesuai". Kemudian } \\
\text { diharapkan responden memilih tombol } \\
\text { kontak langsung }\end{array}$ \\
\hline 5 & $\begin{array}{l}\text { Halaman input } \\
\text { pertanyaan }\end{array}$ & $\begin{array}{l}\text { Anda ingin menulis pesan } \\
\text { langsung kepada operator } \\
\text { layanan }\end{array}$ & $\begin{array}{l}\text { Responden mengisi pesan pada form } \\
\text { yang telah disediakan }\end{array}$ \\
\hline
\end{tabular}

\section{b) Select Participant}

Dalam pengujian usability, tidak bisa ditentukan jumlah responden ideal yang dilibatkan. Namun berdasarkan penelitian [11], ditemukan bahwa dengan jumlah 12-20 responden akan memberikan validitas permasalahan usability yang cukup. Untuk itu, pada penelitian ini melibatkan 15 responden yang dipilih secara acak.

\section{c) Conduct Test}

Adapun tahapan pelaksanaan pengujian usability meliputi

1. Peneliti memberikan pengarahan kepada calon responden

2. Peneliti membacakan satu persatu tugas, kemudian responden langsung mempraktikkannya pada prototype $F A Q$ 
3. Peneliti mencatat waktu, langkah-langkah yang dilakukan oleh responden dan mengidentifikasi apakah responden berhasil atau tidak dalam melaksanakan tugas yang diberikan

4. Setelah sesi pengerjaan tugas selesai, peneliti memberikan kesempatan kepada responden untuk mengutarakan kesulitan serta saran perbaikan sistem FAQ Sesuai dengan konsep Retrospective think aloud (RTA).

\section{d) Analyze Results}

Pada tahapan ini, hasil pengujian usability dianalisa sehingga ditemukan tingkat efektifitas, efisiensi dan kepuasan pengguna. Pada tahapan ini juga diidentifikasi permasalahan yang terjadi pada sistem FAQ sehingga pada tahap selanjutnya bisa dikembangkan rekomendasi.

e) Develop Recomendation

Pada tahapan ini dikembangkan rekomendasi perbaikan berdasarkan hasil analisa yang diperoleh sebelumnya. Rekomendasi perbaikan diberikan dalam bentuk perbaikan pada prototype dan kemudian diuji kembali untuk mendapatkan tingkat usabilitynya.

\section{HASIL DAN PEMBAHASAN}

a) Hasil dan Pembahasan pengujian usability iterasi pertama

Tabel 2. Hasil pengujian Usability

\begin{tabular}{|c|c|c|c|c|c|c|c|c|c|c|c|c|c|c|c|}
\hline \multirow{3}{*}{$\begin{array}{c}\text { Responde } \\
n\end{array}$} & \multicolumn{15}{|c|}{ Tugas } \\
\hline & \multicolumn{3}{|c|}{1} & \multicolumn{3}{|c|}{2} & \multicolumn{3}{|c|}{3} & \multicolumn{3}{|c|}{4} & \multicolumn{3}{|c|}{5} \\
\hline & $\mathrm{n}$ & $t$ & $n^{*} t$ & $\mathrm{n}$ & $t$ & $n^{*} t$ & $\mathrm{n}$ & $t$ & $n^{\star} t$ & $\mathrm{n}$ & $t$ & $\mathrm{n}^{\star} \mathrm{t}$ & $\mathrm{n}$ & $\mathbf{t}$ & $n^{*} t$ \\
\hline 1 & 1 & 15 & 15 & 1 & 45 & 45 & 1 & 20 & 20 & 1 & 18 & 18 & 1 & 20 & 20 \\
\hline 2 & 1 & 5 & 5 & 1 & 20 & 20 & 1 & 15 & 15 & 0 & 20 & 0 & 1 & 13 & 13 \\
\hline 3 & 1 & 20 & 20 & 1 & 40 & 40 & 1 & 10 & 10 & 1 & 9 & 9 & 1 & 16 & 16 \\
\hline 4 & 1 & 21 & 21 & 1 & 38 & 38 & 1 & 8 & 8 & 1 & 16 & 16 & 1 & 20 & 20 \\
\hline 5 & 1 & 15 & 15 & 1 & 56 & 56 & 0 & 40 & 0 & 1 & 15 & 15 & 1 & 12 & 12 \\
\hline 6 & 1 & 14 & 14 & 1 & 40 & 40 & 1 & 30 & 30 & 1 & 15 & 15 & 1 & 10 & 10 \\
\hline 7 & 0 & 14 & 0 & 0 & 45 & 0 & 1 & 30 & 30 & 0 & 20 & 0 & 1 & 21 & 21 \\
\hline 8 & 1 & 30 & 30 & 1 & 53 & 53 & 1 & 40 & 40 & 1 & 10 & 10 & 1 & 22 & 22 \\
\hline 9 & 1 & 40 & 40 & 1 & 43 & 43 & 1 & 25 & 25 & 1 & 20 & 20 & 1 & 22 & 22 \\
\hline 10 & 1 & 30 & 30 & 1 & 40 & 40 & 1 & 40 & 40 & 0 & 15 & 0 & 1 & 22 & 22 \\
\hline 11 & 1 & 20 & 20 & 1 & 18 & 18 & 1 & 38 & 38 & 1 & 20 & 20 & 1 & 12 & 12 \\
\hline 12 & 0 & 26 & 0 & 0 & 8 & 0 & 1 & 40 & 40 & 1 & 21 & 21 & 1 & 10 & 10 \\
\hline 13 & 1 & 50 & 50 & 1 & 10 & 10 & 1 & 30 & 30 & 0 & 10 & 0 & 1 & 20 & 20 \\
\hline 14 & 1 & 55 & 55 & 1 & 15 & 15 & 1 & 40 & 40 & 0 & 8 & 0 & 1 & 10 & 10 \\
\hline 15 & 1 & 20 & 20 & 1 & 8 & 8 & 1 & 40 & 40 & 1 & 9 & 9 & 1 & 10 & 10 \\
\hline Total & $\begin{array}{l}1 \\
3\end{array}$ & $\begin{array}{c}37 \\
5\end{array}$ & $\begin{array}{c}33 \\
5\end{array}$ & $\begin{array}{l}1 \\
3\end{array}$ & $\begin{array}{c}47 \\
9\end{array}$ & $\begin{array}{c}42 \\
6 \\
\end{array}$ & $\begin{array}{l}1 \\
4 \\
\end{array}$ & $\begin{array}{c}44 \\
6 \\
\end{array}$ & $\begin{array}{c}40 \\
6\end{array}$ & $\begin{array}{l}1 \\
0\end{array}$ & $\begin{array}{c}22 \\
6 \\
\end{array}$ & $\begin{array}{c}15 \\
3\end{array}$ & $\begin{array}{l}1 \\
5\end{array}$ & $\begin{array}{c}24 \\
0\end{array}$ & $\begin{array}{c}24 \\
0\end{array}$ \\
\hline
\end{tabular}
berikut:

Berdasarkan data di atas, maka dapat dihitung tingkat usability sistem FAQ Undiksha sebagai

1) Efektivitas

Efektifitas diukur berdasarkan rasio jumlah tugas yang berhasil dilakukan dibandiingkan dengan jumlah tugas keseluruhan. Hasil uji efektivitas sistem FAQ Undiksha adalah sebanyak 76\%. 
Tabel 3. Hasil Uji Efektivitas

\begin{tabular}{cccc}
\hline Tugas & Berhasil & Gagal & Efektifitas \\
\hline 1 & 13 & 2 & $87 \%$ \\
2 & 13 & 2 & $87 \%$ \\
3 & 14 & 1 & $93 \%$ \\
4 & 10 & 5 & $67 \%$ \\
5 & 15 & 0 & $100 \%$ \\
\hline \multicolumn{5}{c}{ Rata-rata } & & $87 \%$ \\
\hline
\end{tabular}

Sesuai dengan Tabel 3, terdapat dua tugas yang mengalami permasalahan usability yaitu tugas ke-4. Berdasarkan pengamatan dan hasil RTA ditemukan permasalahan pada tugas ke-4 adalah letak tombol "kontak langsung" berjauhan dengan tombol "Jawaban Tidak Sesuai" sehingga responden kesulitan untuk menemukan tombol tersebut. Disisi lain, responden menganggap bahwa setelah menekan tombol “Jawaban Tidak Sesuai”, mereka tidak perlu atau tidak ada kesempatan mendapatkan jawaban yang sesuai.

Rekomendasi perbaikan pada permasalahan usability tersebut adalah dengan menyatukan tombol Jawaban Tidak Sesuai dengan tombol Kontak langsung sehingga menjadi "Tidak Sesuai, Saya Ingin Kontak Langsung" sesuai Gambar 9

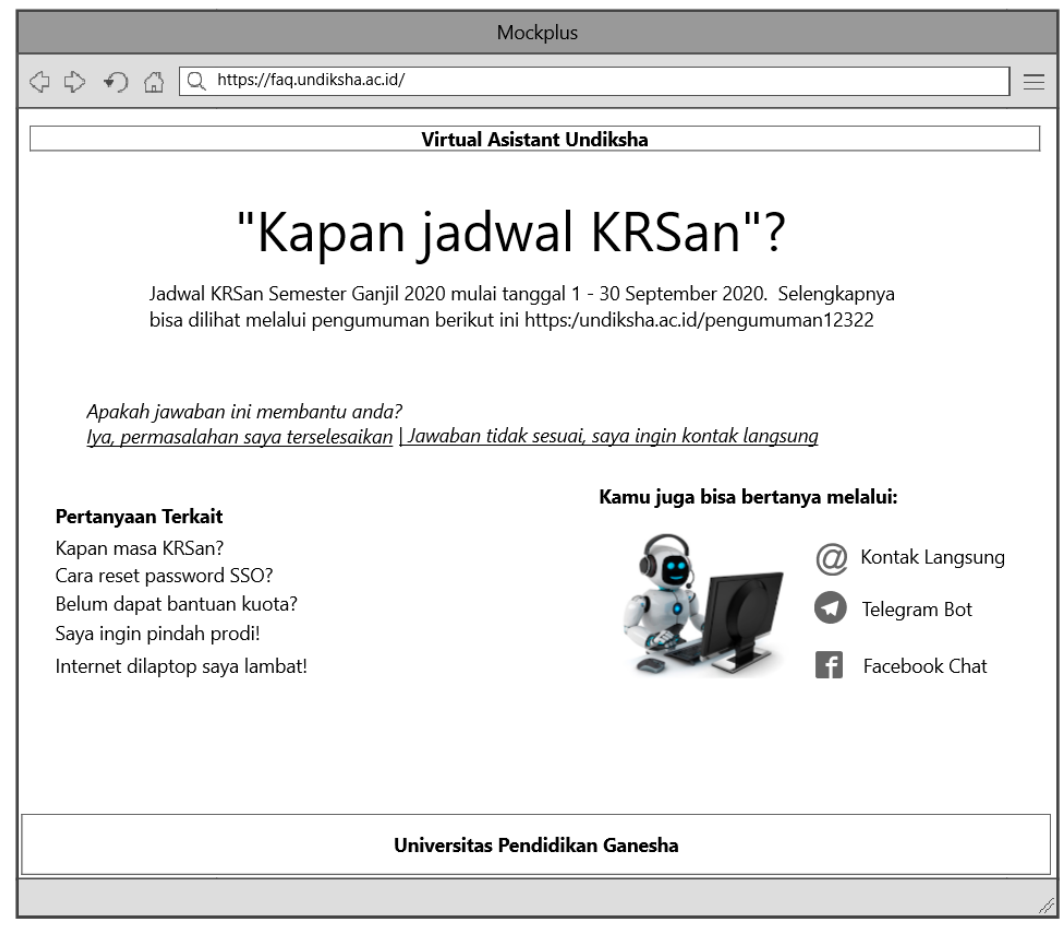

Gambar 9. Perbaikan tugas 4

2) Efisiensi

Efisiensi mengukur waktu yang dibutuhkan responden untuk menyelesaikan tugasnya. Pengukuran efisiensi pada penelitian ini menggunakan teknik Overall Relative Efficiency. Overall Relative Efficiency mengukur rasio waktu yang dibutuhkan oleh responden yang sukses melakukan tugas dibandingkan dengan total waktu yang dibutuhkan oleh seluruh responden.

Tabel 4. Hasil Uji Efisiensi

\begin{tabular}{ccc}
\hline Task & $\mathrm{n}^{\star} \mathrm{t}$ & $\mathrm{t}$ \\
\hline 1 & 335 & 369 \\
2 & 426 & 479 \\
3 & 406 & 446
\end{tabular}




\begin{tabular}{ccc}
\hline Task & $\mathrm{n}^{*} \mathrm{t}$ & $\mathrm{t}$ \\
\hline 4 & 153 & 226 \\
5 & 240 & 240 \\
\hline Total & 1560 & 1760 \\
\hline
\end{tabular}

Berdasarkan tabel di atas, dapat dihitung tingkat efisiensi sistem FAQ Undiksha adalah

$$
\text { Overall Relative Efficiency }=\frac{1560}{1760} \times 100 \%
$$

Overall Relative Efficiency $=89 \%$

hasil uji Overall Relative Efficiency sistem FAQ Undiksha adalah $89 \%$. Hal ini menunjukkan bahwa sistem FAQ Undiksha memiliki tingkat efisiensi yang sesuai standar.

3) Kepuasan Pengguna

Pengujian kepuasan pengguna menggunakan kuisioner SUS. Berikut adalah hasil uji SUS pada Sistem FAQ Undiksha.

Tabel 5. Hasil Uji SUS

\begin{tabular}{|c|c|c|c|c|c|c|c|c|c|c|c|c|c|c|c|c|c|c|c|c|c|}
\hline \multirow{2}{*}{ Resp } & \multicolumn{21}{|c|}{ Hasil SUS } \\
\hline & Q1 & V1 & Q2 & V2 & Q3 & V3 & Q4 & V4 & Q5 & V5 & Q6 & V6 & Q7 & V7 & Q8 & V8 & Q9 & V9 & Q10 & V10 & Total \\
\hline 1 & 5 & 4 & 4 & 1 & 3 & 2 & 1 & 4 & 5 & 4 & 1 & 4 & 5 & 4 & 1 & 4 & 4 & 3 & 3 & 2 & 80 \\
\hline 2 & 2 & 1 & 3 & 2 & 4 & 3 & 2 & 3 & 4 & 3 & 1 & 4 & 4 & 3 & 2 & 3 & 5 & 4 & 3 & 2 & 70 \\
\hline 3 & 4 & 3 & 2 & 3 & 3 & 2 & 1 & 4 & 5 & 4 & 2 & 3 & 5 & 4 & 1 & 4 & 5 & 4 & 3 & 2 & 82.5 \\
\hline 4 & 5 & 4 & 2 & 3 & 3 & 2 & 2 & 3 & 4 & 3 & 1 & 4 & 5 & 4 & 1 & 4 & 5 & 4 & 1 & 4 & 87.5 \\
\hline 5 & 4 & 3 & 1 & 4 & 3 & 2 & 1 & 4 & 5 & 4 & 1 & 4 & 4 & 3 & 2 & 3 & 3 & 2 & 2 & 3 & 80 \\
\hline 6 & 4 & 3 & 1 & 4 & 4 & 3 & 1 & 4 & 4 & 3 & 2 & 3 & 4 & 3 & 2 & 3 & 5 & 4 & 1 & 4 & 85 \\
\hline 7 & 3 & 2 & 2 & 3 & 5 & 4 & 3 & 2 & 5 & 4 & 2 & 3 & 4 & 3 & 1 & 4 & 5 & 4 & 1 & 4 & 82.5 \\
\hline 8 & 2 & 1 & 3 & 2 & 5 & 4 & 1 & 4 & 5 & 4 & 2 & 3 & 4 & 3 & 3 & 2 & 5 & 4 & 2 & 3 & 75 \\
\hline 9 & 3 & 2 & 3 & 2 & 5 & 4 & 2 & 3 & 5 & 4 & 3 & 2 & 5 & 4 & 3 & 2 & 4 & 3 & 1 & 4 & 75 \\
\hline 10 & 3 & 2 & 2 & 3 & 5 & 4 & 1 & 4 & 5 & 4 & 1 & 4 & 5 & 4 & 2 & 3 & 4 & 3 & 1 & 4 & 87.5 \\
\hline 11 & 4 & 3 & 2 & 3 & 4 & 3 & 2 & 3 & 5 & 4 & 1 & 4 & 5 & 4 & 3 & 2 & 4 & 3 & 1 & 4 & 82.5 \\
\hline 12 & 4 & 3 & 3 & 2 & 4 & 3 & 1 & 4 & 3 & 2 & 2 & 3 & 3 & 2 & 1 & 4 & 5 & 4 & 2 & 3 & 75 \\
\hline 13 & 4 & 3 & 2 & 3 & 5 & 4 & 2 & 3 & 4 & 3 & 2 & 3 & 5 & 4 & 3 & 2 & 4 & 3 & 4 & 1 & 72.5 \\
\hline 14 & 5 & 4 & 2 & 3 & 5 & 4 & 1 & 4 & 3 & 2 & 1 & 4 & 4 & 3 & 2 & 3 & 5 & 4 & 2 & 3 & 85 \\
\hline \multirow[t]{2}{*}{15} & 4 & 3 & 2 & 3 & 5 & 4 & 2 & 3 & 5 & 4 & 2 & 3 & 5 & 4 & 2 & 3 & 5 & 4 & 1 & 4 & 87.5 \\
\hline & & & & & & & & & & & & & & & & & & & \multicolumn{2}{|c|}{ SUS Score } & 80.5 \\
\hline
\end{tabular}

Nilai SUS sistem FAQ Undiksha adalah 80.5. Berdasarkan hal tersebut, dapat disimpulkan bahwa sistem FAQ Undiksha sudah memenuhi aspek kepuasan pengguna, dimana score SUS standar adalah 68.

\section{SIMPULAN DAN SARAN}

Pada penelitian ini telah dikembangkan prototype FAQ dengan pendekatan UCD. Pengembangan prototype FAQ bertujuan untuk memudahkan penyedia layanan berkomunikasi dengan pengguna layanan secara efektif dan efisien yang tidak dibatasi oleh waktu. Pendekatan pengembangan prototype FAQ menggunakan UCD dengan tujuan agar fitur dan desain sesuai dengan kebutuhan pengguna. UCD meliputi Understand and specify the context of use, Specify the user and organizational requirements, Produce design solutions (prototypes) dan Evaluate designs with users against requirements. Pada pengembangan prototype ini, dihasilkan prototype yang tediri dari fitur Halaman Utama FAQ, Halaman Jawaban, Halaman Penilaian dan Halaman Input Pertanyaan. Usability prototype ini dievaluasi sesuai standar ISO 9241-11 yang terdiri dari efektifitas, efisiensi dan kepuasan pengguna. Pada iterasi pertama didapatkan tingkat efektifiitas sebanyak $87 \%$ dengan rekomendasi perbaikan pada tugas ke-4 yaitu terkait aksi yang dilakukan pengguna jika jawaban yang tampil tidak menyelesaikan masalah. Sedangkan atribut kualitas efisiensi bernilai 98\% dan kepuasan pengguna bernilai 80.5 dari standar 68 . Pada iterasi kedua dilakukan perbaikan prototype ada tugas ke-4 sehingga didapakan hasil uji efektifitas menjadi 93\%. Dari penelitian ini dapat disimpulkan bahwa dengan menerapkan UCD dimana pengguna dilibatkan langsung dalam merancang sistem, maka masalah usability bisa diminimalisir. Hal ini terlihat pada penelitian ini hanya terdapat satu masalah usability pada 
prototype $F A Q$ dengan nilai awal yang tidak terlalu signifikan. Pada penelitian selanjutnya, perlu dilakukan pengujian keterkaitan antara penggunaan pendekatan UCD dengan hasil pengujian Usability.

\section{UCAPAN TERIMAKASIH}

Terima kasih kepada LPPM Undiksha yang telah membiayai penelitian ini melalui dana DIPA Undiksha tahun 2020. Ucapan terima kasih juga disampaikan kepada UPT TIK Undiksha yang menfasilitasi uji coba dan implementasi prototype FAQ Undiksha ini.

\section{DAFTAR PUSTAKA}

[1] Bhojaraju G, "KNOWLEDGE MANAGEMENT: WHY DO WE NEED IT FOR CORPORATES," Malaysian J. Libr. Inf. Sci. (ISSN 1394-6234), vol. 10, no. 2, pp. 37-50, 2005.

[2] W. Kurnia Sari and K. Ditha Tania, "Penerapan Knowledge Management System (KMS) Berbasis Web Studi Kasus Bagian Teknisi dan Jaringan Fakultas IImu Komputer Universitas Sriwijaya," ISSN Print, vol. 6, no. 2, pp. 2085-1588, 2014.

[3] K. Iskandar, "Pengembangan Knowledge Management System pada Bina Nusantara Berbasis Microsoft Sharepoint 2010," ComTech Comput. Math. Eng. Appl., vol. 5, no. 1, p. 429, 2014, doi: 10.21512/comtech.v5i1.2637.

[4] P. Ratwiyanti, Y. Munsaidah, and R. Dewi, "ANALISIS KNOWLEDGE MANAGEMENT SYSTEM READINESS DI UNIVERSITAS AMIKOM PURWOKERTO BERDASARKAN ASPEK PEOPLE , PROCESS , TECHNOLOGY," J. Sist. dan Inform., vol. 9, no. 1, pp. 166-175, 2020.

[5] A. Ali, R. N. H. Nor, R. Abdullah, and M. A. A. Murad, "Developing conceptual governance model for collaborative knowledge management system in public sector organisations," J. Inf. Commun. Technol., vol. 15, no. 2, pp. 171-191, 2016.

[6] D. Green and J. M. Pearson, "Development of a Web site usability instrument based on ISO 9241-11," J. Comput. Inf. Syst., vol. 47, no. 1, pp. 66-72, 2006, doi: 10.1080/08874417.2006.11645940.

[7] J. Nielsen, "Usability 101: Introduction to Usability," Nielsen Norman Gr., p. Articles, 2012, doi: 10.1145/1268577.1268585.

[8] I. K. R. Arthana, I. M. A. Pradnyana, and G. R. Dantes, "Usability testing on website wadaya based on ISO 9241-11," in Journal of Physics: Conference Series, 2019, vol. 1165, no. 1, p. 12012.

[9] J. Y. Mao, K. Vredenburg, P. W. Smith, and T. Carey, "The state of user-centered design practice," Commun. ACM, vol. 48, no. 3, pp. 105-109, 2005, doi: 10.1145/1047671.1047677.

[10] J. Nielsen, "Guerrilla $\mathrm{HCl}$ : Using discount usability engineering to penetrate the intimidation barrier," Cost-justifying usability, pp. 245-272, 1994.

[11] R. Alroobaea and P. J. Mayhew, "How many participants are really enough for usability studies?," Proc. 2014 Sci. Inf. Conf. SAI 2014, pp. 48-56, 2014, doi:

10.1109/SAI.2014.6918171. 